\title{
Copper Isotope Fractionation by Diffusion in Basaltic Melts
}

\author{
PENG NI ${ }^{1}$, ANAT SHAHAR ${ }^{1}$ AND YOUXUE ZHANG ${ }^{2}$
}

${ }^{1}$ Earth and Planets Laboratory, Carnegie Institution for Science

${ }^{2}$ University of Michigan

Presenting Author: pengni@umich.edu

Since the advancement in precise $\mathrm{Cu}$ isotope analysis about 20 years ago, various types of geological and planetary samples have been investigated for their $\mathrm{Cu}$ isotopic compositions. These studies found that $\mathrm{Cu}$ isotopes show limited equilibrium fractionation at magmatic temperatures. For example, mid-ocean ridge basalts, ocean island basalts, komatiites, and peridotites all have similar $\mathrm{Cu}$ isotopic compositions with an average $\mathrm{d}^{65} \mathrm{Cu}$ of $0.07 \%$. In contrast, natural samples that experienced kinetic processes (e.g. lunar samples, trinitite glasses, and tektites) show $\mathrm{Cu}$ isotope fractionation as high as $12.5 \%$, making it especially important to understand how $\mathrm{Cu}$ isotopes are fractionated by kinetic processes, such as evaporation and diffusion.

Diffusion can cause isotopic fractionation because lighter isotopes of an element diffuse faster than its heavier isotopes. More quantitatively, the diffusivities of two isotopes of an element are related to their masses via: $D_{\mathrm{i}} / D_{\mathrm{j}}=\left(m_{\mathrm{j}} / m_{\mathrm{i}}\right)^{\beta}$, where $D_{\mathrm{i}}, D_{\mathrm{j}}, m_{\mathrm{i}}$, and $m_{\mathrm{j}}$ are the diffusivities and molecular masses of the two isotopes respectively, and $\beta$ is an empirical factor. Understanding how diffusion fractionates $\mathrm{Cu}$ isotopes in silicate melts relies heavily on knowledge of the $\beta$ factor.

In this study, $\mathrm{Cu}$ isotope profiles in diffusion couple experiments are measured to determine the $\beta$ factor for $\mathrm{Cu}$ in basaltic melts. A micromill loaded with tungsten-carbide drill bits was used to sample the experimental product at different distances from the diffusion couple interface. The sampled glass powders were dissolved and $\mathrm{Cu}$ was purified using Bio-Rad columns loaded with AG1-X8 resin. The purified $\mathrm{Cu}$ cut was then measured for its isotopic composition using a Nu Plasma II at the Carnegie Institution for Science.

Based on the measured $\mathrm{Cu}$ isotope profiles of two $\mathrm{Cu}$ diffusion couple experiments at 1314 and $1397^{\circ} \mathrm{C}$, similar $\beta$ factors of 0.177 and 0.157 are obtained. These are the first experimental data on the $\beta$ factor for $\mathrm{Cu}$ in silicate melts and are crucial for understanding $\mathrm{Cu}$ isotope fractionation in kinetic processes. For example, during planetesimal evaporation in the early stages of Earth formation or tektite formation, significant $\mathrm{Cu}$ isotope fractionation could occur simply due to diffusive transport of $\mathrm{Cu}$ to the melt surface. 